\title{
nature medicine
}

VOLUME 9 • NUMBER 3 • MARCH 2003

\section{Weapons of mass protection}

In late January, President Bush proposed a new plan to protect Americans from biological warfare. Nearly $\$ 6$ billion has been allocated to expedite development of new vaccines and drugs against bioweapons. Congress will also consider legislation to approve another $\$ 10$ billion for HIV/AIDS initiatives, including significant funds for HIV vaccine development. Although this is reassuring news for citizens of industrialized nations, there is no money earmarked in the fiscal year 2004 budget (see News, page 248) for advancing vaccine strategies for the most lethal threats to developing nations-diseases like malaria and tuberculosis.

The campaign for universal childhood immunization, which was started in 1985 by the United Nations Children's Emergency Fund, has been one of the world's most significant public health achievements. By the early 1990s, more than $70 \%$ of children in developing countries received vaccines for common diseases, up from zero in some parts of sub-Saharan Africa. But progress has stalled, and approximately $25 \%$ of the world's children still have no protection from diseases for which effective vaccines exist. This year, the supply of vaccines against diphtheria, polio, tetanus, yellow fever and pertussis in many developing nations will fall short of demand. Compounding this problem is the lack of a truly efficacious vaccine for tuberculosis, or any vaccine at all for malaria or HIV; without them, more than 3 million children die from these diseases each year.

Why has the vaccine supply dwindled? Why is there so little funding for new vaccines? The Wellcome Trust estimates that worldwide malaria research amounted to $\$ 84$ million last year, with only a small portion dedicated to vaccine development. This is minuscule relative to spending on disease concerns of indus- trialized nations, such as asthma (with approximately $\$ 800$ million in funding). Because companies foresee trivial profits from vaccines that primarily benefit developing nations, they undertake very little research on them. Some estimates put a formidable $\$ 500$ million price tag on bringing a new vaccine to market. Companies are unwilling to take on the costly process of manufacturing vaccines without a guaranteed and sizeable market at the end of the process. While many academic labs work independently on discovering new vaccine targets, very few have the capacity to take a vaccine from discovery to clinical trial.

The question, therefore, is how to make it economically feasible and attractive for scientists and industry to address major global health problems and return a profit at the same time. An overriding paradigm is that industry follows the market. If a guaranteed market exists (or is created with the right incentives), successful vaccines could follow. After a company has spent $\$ 500$ million to bring an effective vaccine to market, it will want to recoup its expenses and make a profit. But it is likely that an argument will be made that developing nations deserve the vaccine at low prices-enough to cover manufacturing, but not the prior research and development costs.

Several economists have proposed an alternative scheme in which the United Nations or philanthropic ventures could pledge to purchase (for an agreed minimum price) a proven effective vaccine each year. Under this proposal, governments would have no liability and no expense until an approved vaccine is produced. This initiative would merit the initial investment. Philanthropic and governmental aid to Africa alone now totals $\$ 16$ billion per year; a small percentage of this aid could be allocated to pay for vaccines.

Among other financial incentives, tax relief for companies working on malaria, tuberculosis and HIV vaccines has been proposed as an alternative-but at a much higher cost to governments, and with no guarantee that a successful vaccine would ever be produced. Respect for intellectual property and patent protection are also incentives; there remains a need to prevent 'piracy' through better surveillance mechanisms and international laws. Selling the same vaccine for more in the US than in Africa (multitiered pricing) may also be a viable alternative. Vaccine production is a relatively fixed-cost business; revenue from each additional dose sold at a price above the production cost could directly contribute to profits.

New vaccines will also require more partnerships between the public and private sectors. The private sector alone may not be able to develop vaccines for all diseases-but many scientists are working on improving targets for new vaccines. Combined efforts between the public and private sectors to research, manufacture, and field test vaccines must be encouraged. Joint ventures could potentially reduce costs and yield benefits more rapidly.

While more scientists and companies may be convinced to direct their efforts to vaccine development, there are still the questions of who would fund neglected diseases. But when some of the obstacles are removed with implementation of these incentives, perhaps the answers to these questions will begin to appear. Our first priority should be to create a market for malaria, tuberculosis and HIV vaccines. Doing so could harness the resources and expertise of the private sector and the knowledge of many independent scientists in order to save the lives of millions. 